\title{
Challenges researchers need to consider when dealing with regulators
}

\author{
Joe Smith $\cdot$ Heidi Mitchell
}

Received: 31 January 2014/ Accepted: 8 April 2014/Published online: 28 May 2014

(C) The Author(s) 2014. This article is published with open access at Springerlink.com

\begin{abstract}
Australia's gene technology regulation will be used to illustrate some key challenges researchers should consider in the interface between research and regulation. These challenges result from the variety of legal obligations as well as from the different viewpoints, motivations and assumptions of researchers and regulators. Australia's gene technology regulation is based on a framework comprising both Commonwealth and corresponding State and Territory legislation designed to manage risks posed by genetically modified organisms (GMOs). While the Gene Technology Regulator is an essential decision maker, researchers may also need to interact with other regulators when developing products for various uses, such as those tasked with food safety, agricultural and veterinary chemicals, therapeutics and biosecurity. Each one of those regulators must satisfy their relevant legislation and may, therefore, require different information from the researcher. The legislation under which each regulator is required to operate is often prescriptive with regard to the processes that must be followed and the considerations that must be taken into account.
\end{abstract}

Conference Proceedings "Science into Policy, improving uptake and adoption of research conference" 11th to 13th November 2013 in Brisbane, Australia, a conference sponsored by the OECD Co-operative Research Programme on Biological Resource Management for Sustainable Agricultural Systems.

J. Smith · H. Mitchell ( $₫)$

Office of the Gene Technology Regulator, Australian

Government Department of Health, MDP 54,

GPO Box 9848, Canberra, ACT 2601, Australia

e-mail: heidi.mitchell@health.gov.au
Amendments to the legislation are possible but may be slow compared with the fast-paced and adaptive nature of scientific research. Other challenges may include: the desire of researchers to protect intellectual property versus the public expectation of transparency from regulators; or the notion in researchers that genetically modified organisms are simply organisms versus the regulator's legislation and risk oriented view. Challenges arising from differences in focus and expectations can be overcome by improving dialogue and engagement between regulators and researchers. This will also lead to a more robust regulatory system.

Keywords Gene technology · Regulation · Challenges · Research

\section{Introduction}

Most countries have regulatory systems based on legislation for processes or products over which the government wants to exercise control. The conduct of scientific research can be overseen by a number of different regulators with different objectives and remits. This is particularly the case for research and products involving new technologies, such as work with gene technology, where society has expressed concern and demanded assurances that the products are safe. This makes dealing with regulation one of the skills needed to work in biotechnology research.

The interface between researchers and those regulating their work can pose some challenges because of the differing perspectives of those involved. Researchers may see regulation as an unnecessary 
impost on their research, and perceive bureaucrats as demanding more paperwork which gets in the way of their 'real' work. The regulators may see their role differently--that they are protecting the researcher and the wider community from risks. As a result of the contentious nature of gene technology, a regulator can provide assurances to the community that there is appropriate oversight of the work which can in turn assist the researcher by supplying a 'social licence' to operate (Lacey and Lamont 2013) for the researcher.

This paper will explore some of the key considerations that researchers should bear in mind when approaching the challenges at the interface between research and regulation, using Australia's gene technology regulatory system as an example.

\section{Australia's gene technology regulatory scheme}

Work with gene technology in Australia is regulated under the Gene Technology Act 2000 (the GT Act) and the Gene Technology Regulations 2001 and a suite of corresponding State and Territory legislation. The GT Act regulates 'dealings' with genetically modified organisms (GMOs), from initial experimental work in the laboratory through to commercial release, to protect human health and the environment. Information gained at each step is used as the basis for a science-based risk assessment, with management conditions commensurate with the assessed risk. The Australian scheme is broadly similar to regulatory systems in many other countries. It accords with the principle for biotechnology assessment established in the early 1990s by the Organisation of Economic and Cultural Development (OECD) (OECD 1992, 1993), including the 'blue book' concept of a 'step by step' process proceeding from confinement to open to the environment using the knowledge gained from each step to develop familiarity (OECD 1986).

The GT Act establishes an independent statutory office holder, the Gene Technology Regulator (the Regulator), to administer the regulatory scheme. The Regulator has extensive powers to monitor and enforce the legislation and is supported in his role by the Office of the Gene Technology Regulator (OGTR). The Regulator makes decisions under the GT Act, but changes to legislation and regulations must be made by government.

The gene technology legislation was developed with extensive community consultation. As a result of the consultation, a number of key principles were established including that:
- regulation operates as a part of an integrated legislative framework with other Australian agencies;

- the regulatory process is transparent and consultative; and

- independent, science based assessments are used.

These are good principles and they underpin a regulatory scheme that has been demonstrably effective. However, they can create certain challenges that researchers may face when interacting with the gene technology regulatory scheme.

\subsection{Which regulatory system applies?}

As in many countries where new legislation has been developed, Australia's gene technology legislation attempts to 'fill a gap' between existing pieces of legislation. Importantly, the suite of regulation is designed to avoid duplication and integrate the activities of regulatory authorities with complementary responsibilities and expertise.

For some research activities approvals from different regulators may be needed. This arises from the different regulators having different objectives and different protection goals. For example, a GM plant imported from overseas may require authorisation, both under the GT Act to contain the GMO and the Quarantine Act 1908 , because the plant might carry pests and diseases.

In the case of GM crops that are insect resistant or herbicide tolerant, growing these crops in Australia would require approval from the Regulator. They would also require approval from the Australian Pesticides and Veterinary Medicines Authority (APVMA), which is responsible for regulating all agricultural chemicals, to register the insecticide product produced in the GM plant and/or approve application of the herbicide to which the GM plants are tolerant. A similar system exists in the European union (EU) (Ehlers 2011).

The requirement for multiple regulatory approvals means researchers may need to negotiate several sets of regulations if they wish to commercialise a GMO. A researcher/developer therefore needs to understand what requires authorisation, who can provide the authorisation and what they need to do to obtain the authorisation. To help assist researchers, the regulatory agencies in Australia work together to avoid duplication and ensure that thorough coordinated assessments of parallel applications are undertaken and, wherever possible, that the timing of decisions by the agencies coincides. There are also reciprocal 
requirements for the various regulators to seek and provide advice to each other to facilitate co-ordination of regulation.

The integrated legislative framework may also mean that a researcher has to determine which regulatory agency has oversight of their work. This was illustrated by researchers working with non-GM Wolbachia-inoculated Aedes aegypti mosquitoes, who were unsure which regulator should authorise their field trial (De Barro et al. 2011). Such a situation requires the researcher to have a clear understanding of the regulatory schemes in place and for regulators to communicate clearly with researchers about their role.

\subsection{National and state regulation}

In many countries or jurisdictions, regulation may be administered at a local rather than a national level. This may be due to overlap in areas of responsibility with state and federal laws or, in the case of Europe for example, at the country rather than the EU level.

Australia, like many countries, has state governments as well as a federal (Commonwealth) government, and there is a division of responsibilities between federal and state governments. To ensure complete regulatory coverage for gene technology, the scheme was set up with a federal GT Act and an agreement (Intergovernmental Gene Technology Agreement 2001) that the States and Territories would pass corresponding legislation. This 'national scheme' was considered to be better than each State and Territory having their own scheme (Ludlow 2004). It means that all organisations in Australia in all jurisdictions are regulated in the same way and all the corresponding gene technology legislation is administered by the Regulator.

However, from a researcher's perspective this can create some complexities. A researcher needs to understand whether they are regulated under State or federal legislation depending on their organisation's legal status. This is particularly important following any changes to the federal law as some States have to pass their own updated legislation, and this may lead to a period of mismatch (The Allen Consulting Group 2011).

Researchers may also have to navigate regulation that is enacted for different reasons. For example in Australia, the GT Act is focussed on protecting human health and the environment. However, within the national scheme, States and Territories can introduce state-specific legislation to address trade and marketing concerns [Gene Technology (Recognition of
Designated Areas) Policy Principle 2003]. In some States, this means that researchers need to apply for additional approvals to do research or conduct trials. It has been suggested that this has created an inconsistent and lengthy path to market for GMOs (Gibbs et al. 2013) and may be inhibiting research (Tasmanian Department of Primary Industries, Parks, Water and Environment 2013).

\section{Gene technology regulated by legislation}

In most jurisdictions work with gene technology is regulated by legislation, which provides a set of rules. Laws impose requirements and prohibitions and penalties for non-compliance, so the legislation must provide clear boundaries to provide certainty for researchers. The administration of legislation by a regulator must, in turn, be uniform, consistent and impartial. The apparent rigidity of legislation can be challenging when regulating science which is, by nature, changing and fast-paced and involves innovative approaches.

Laws are made and revised by governments, and administered by regulators. The laws themselves often contain prescriptive definitions, requirements and timeframes. It is possible for researchers to influence the development of legislation at the drafting or amending stage, where risks may have changed due to new information or other factors and indeed researchers are encouraged to engage in this process. However, once legislation is enacted the rules are set and must be implemented by the Regulator. This means that a researcher needs to plan ahead and consider regulation, for example to avoid potential issues with statutory assessment times impacting on their ability to plant a GM field trial or to make amendments to applications after they have been submitted. Regulators can only accommodate or consider requests from researchers within the framework of the legislation. In Australia, the GT Act allows the Regulator to agree, after assessment of any risks, to certain changes to authorisations and requirements after the licences have been issued. These provisions are used frequently by researchers to vary their original proposal in light of changed circumstances, with $75 \%$ of field trial licences varied at least once.

A challenge for both regulators and researchers relates to anticipating the future when advancing any changes to legislation. This point was raised in De Barro et al. (2011) in conjunction with regulation of Wolbachia-inoculated mosquitos which he cites as 
an example of how science is "leading to advances that outstrip existing regulatory frameworks and underscores the need for researchers to engage proactively with regulators to inform them of the implications their science has for existing policy, legislation and regulation".

The ability of legislation to respond to, and even anticipate, advances in technology is also clearly illustrated by the debate around regulation of new plant breeding technologies and how these fit into current regulatory schemes internationally (FSANZ 2013; Heap 2013; Kuzma and Kokotovich 2011). Different countries have different triggers for regulation of biotechnology products, usually effected by legal definitions. Some jurisdictions (including the EU and Australia) have a technology 'process' trigger where organisms or food are subject to regulation as GM if the techniques involved are defined as GM in legislation. Other jurisdictions (including Canada and New Zealand for organisms) have a 'product' trigger such as novelty of the introduced trait. This has implications for researchers operating internationally as to whether certain activities are regulated. A recent review of Australia's gene technology legislation (The Allen Consulting Group 2011) also recognised that the development of new technologies is moving faster than the regulations and is thus testing their limits. The Australian government has committed to looking at how this can be resolved (All governments' response 2013).

\section{Science based risk assessment}

As with most countries, the Australian system for regulation of GMOs is underpinned by science-based risk assessment. This requires scientific data to verify a researcher's assertions, preferably from publicly available, peer-reviewed sources. However, the information required for the purposes of risk assessment is often not necessarily the most straightforward or interesting for a researcher to provide. Unlike some schemes, the Australian gene technology legislation does not allow a consideration of benefits. This means that much of the data that a researcher may collect is not required for use in assessments by the Regulator.

Moreover, in many cases the data that regulators are looking for is a negative result, for example showing no change in the weediness of a GM plant compared with the non-GM parent, whereas researchers are usually looking for improvements. For the release of some crop plants there can also be key pieces of information missing from the literature about important aspects of the crop biology, which may not be important for production but essential for regulatory risk assessment. For example, scientists developing GM sugarcane became aware of the paucity of information on flowering and seed set in commercial sugarcane in Australia (Bonnett et al. 2007). It can be challenging for a molecular biologist who is interested in developing a GM plant to be asked basic ecology questions about the unmodified parent plant.

The Regulator has tried to describe clearly the information that is required for a risk assessment, both in the risk assessment framework, which describes the approach to conducting risk assessments as well as the quality of evidence that is required (OGTR 2013b), and in application forms. These documents are periodically revised, for example, the plant field trial application form was significantly enhanced in 2013 to provide links to example answers to assist with completing the form by illustrating the kind of information required for conducting risk analysis. ${ }^{1}$ The new application form also incorporates aspects of the new weed risk assessment methodology used for assessments of GMOs (Keese et al. 2013). This material is intended to clarify what information is required for a GM plant field trial to assist the researcher to collect and provide the necessary data.

\section{Transparency and consultation in regulation}

Stakeholder confidence depends both on having robust regulatory systems and effective stakeholder communication. Transparency and predictability in regulation is essential--the regulated community and the public must understand what a regulator does, why they do it, and the basis on which decisions are made.

When the Australian regulatory scheme for gene technology was established, governments sought to recognise and acknowledge both the potential of gene technology to contribute to society and community concerns over its development and deployment. The extensive consultation conducted during development of the regulatory scheme reflected the emphasis placed on community input and participation in the decision-making process. A recent survey of public attitudes to gene technology by the Australian government Department of Industry confirmed that there is a strong view in the

\footnotetext{
${ }^{1}$ http://www.ogtr.gov.au/internet/ogtr/publishing.nsf/Content/ dirform-new-htm.
} 
community that public consultation improves the quality of regulation of gene technology (55\% agreed, Ipsos-Eureka 2010).

Australia's gene technology regulatory system requires consultation with relevant government agencies, technical experts and the public on applications for release of GMOs into the environment. The applicant also has an opportunity to comment on the risk assessment and risk management plan prepared for their proposed field trial or commercial release, to ensure that it is accurate and that the licence conditions are practicable and likely to achieve desired outcomes. However, the requirement to make information publicly available may, in some cases, generate challenges for researchers, with unexpected or even unwanted, interest from the media or community organisations.

Although the GT Act contains provisions to maintain confidentiality of commercial information, there is a public interest test associated with this, which is seen as particularly important for a commercial release of a GMO. This has challenged researchers who, for various reasons, may not want to reveal certain details of their research. It also requires that researchers are aware of which pieces of their research actually need to be protected, and which are already in the public domain. The GT Act also requires that GM field trial site details are publicly available thus ensuring transparency and avoiding potential accusations that information is being hidden from the public. This has led to researcher concerns about possible vandalism of sites as has happened in some countries (Houllier 2012, and data collected by Kuntz). ${ }^{2}$ Fortunately such incidents have not been widespread in Australia, with only once incident to date (OGTR 2013a).

While it is a particular strength of the regulatory system, the requirement for transparency and openness about the research being conducted can also mean that researchers have to think about how to present their work to the public. Scientists are often accused of 'group-think' (as described in Whyte 1989) and may not always appreciate that sections of the community may not share their views about the benefits of their research, may misunderstand their motives, or may find the language they use confusing. Media interest in GM research may also require that researchers talk about their research with journalists, who may not have a technical understanding of the work, or be sympathetic to its outcomes. It can

\footnotetext{
$\overline{2}$ http://ddata.over-blog.com/xxxyyy/1/39/38/37/public-researchvandalized.pdf.
}

also create an unwelcome focus on a particular organisation, with campaigns being directed at organisations (e.g. Greenpeace 2010, 2011). To engage effectively in the public discourse, researchers will have to embrace an increasingly diverse range of mechanisms such as social media, video messaging and public debate (which were used, for example, in discussions of a GM wheat trial in the $\mathrm{UK}^{3}$

\section{Communication}

One of the challenges that researchers sometimes face when dealing with regulators is a lack of a common understanding. Effective communication is critical both for researchers to gain a clear understanding of the regulatory scheme and for regulators to understand the challenges faced by the researchers. There are many mechanisms by which researchers can communicate to enhance their understanding of the regulatory framework and to promote awareness of their concerns within it. These mechanisms can range from researchers querying aspects of a risk assessment through to applying to serve on a technical advisory committee or advocating changes to legislation through a formal review process. Although it must be recognised that researchers are not always unbiased participants in this process (Bartsch 2014).

The Australian gene technology legislation has been independently reviewed twice, in 2006 and 2011 (Commonwealth of Australia 2006; The Allen Consulting Group 2011) and the supporting regulations are periodically reviewed. These reviews are informed by stakeholder input, including researchers within the regulated community, who provide important perspectives as to how the legislation can be improved. Such reviews provide critical opportunities for researchers to influence the direction of the legislation and to try to address challenges within the regulatory scheme. Historically, these reviews of regulations have used experience and new information to reduce the regulatory oversight of particular dealings, commensurate with the risk they pose. Researchers can also influence the administrative and risk assessment processes used to implement regulations, for example, as occurred with suggestions to adapt established methodology for weed risk assessment to strengthen environmental risk assessment of GM plants (Keese et al. 2013).

\footnotetext{
$\overline{3}$ http://www.senseaboutscience.org/pages/rothamsted-appeal. html.
} 


\section{Conclusions}

In order for both regulators and researchers to deliver important societal goals, it is crucial that they communicate to understand the landscape from their different viewpoints. Science is the common language and getting the science right is pivotal to the credibility of both the researcher and regulator. As scientific understanding continues to advance, regulatory systems require active engagement from regulators, researchers and the public in their respective spheres of influence to maintain effective, fit for purpose regulation that addresses, and is seen to address, society's needs in terms of enabling safe access to new technology.

Acknowledgments The authors would like to thank Dr Peter Thygesen and Dr Robyn Cleland for their helpful suggestions on this manuscript.

Open Access This article is distributed under the terms of the Creative Commons Attribution License which permits any use, distribution, and reproduction in any medium, provided the original author(s) and the source are credited.

\section{References}

All Governments' Response to the recommendations of the 2011 Review of the Gene Technology Act 2000 (2013). https://www.health.gov.au/internet/main/publishing.nsf/ Content/gene-techact-review. Accessed 2 April 2014

Bartsch D (2014) GMO regulatory challenges and science: a European perspective. J Verbrauch Lebensm (in press)

Bonnett GD, Berding N, Morgan T, Fitzgerald P (2007) Implementation of genetically modified sugarcane--the need for a better understanding of sexual reproduction. Proc Aust Soc Sugar Cane Technol 29:258-266

Commonwealth of Australia (2006) Statutory review of the Gene Technology Act 2000 and the Gene Technology Agreement, Canberra, Australia

De Barro PJ, Murphy B, Jansen CC, Murray J (2011) The proposed release of the yellow fever mosquito, Aedes aegypti containing a naturally occurring strain of Wolbachia pipientis, a question of regulatory responsibility. J Verbrauch Lebensm 6:33-40

Ehlers U (2011) Interplay between GMO regulation and pesticide regulation in the EU. J Verbrauch Lebensm 6(Suppl 1): S61-S64

FSANZ (2013) New plant breeding techniques. Workshop report. http://www.foodstandards.gov.au/publications/Pages/ New-plant-breeding-techniques-workshop-report.aspx. Accessed 2 April 2014

Gibbs C, Harris-Adams K, Davidson A (2013) Review of selected regulatory burdens on agriculture and forestry business. ABARES (Report to client prepared for the Department of Agriculture's Agricultural Productivity Division), Canberra, Australia
Greenpeace (2010) Spliced bread. The threat of genetically engineered wheat in Australia. http://www.greenpeace. org/australia/PageFiles/293988/ge-spliced-bread-report.pdf. Accessed 2 April 2014

Greenpeace (2011) Australia's wheat scandal. The biotech takeover of our daily bread. http://www.greenpeace.org/ australia/PageFiles/321712/Greenpeace\%20Report_Australia's\% 20Wheat\%20Scandal.pdf. Accessed 2 April 2014

Heap B (2013) Europe should rethink its stance on GM crops. Nature 498:409

Houllier F (2012) Biotechnology: bring more rigour to GM research. Nature 491:327. doi:10.1038/491327a

Ipsos-Eureka (2010) Community attitudes to biotechnology 2010 , conducted for the Department of Innovation, Industry, Science and Research. http://www.innovation.gov.au/ industry/nanotechnology/PublicAwarenessandEngagement/ Documents/CommunityAttitudesBiotechnology2010.pdf. Accessed 2 April 2014

Keese PK, Robold AV, Myers RC, Weisman S, Smith J (2013) Applying a weed risk assessment approach to GM crops. Transgenic Res. doi:10.1007/s11248-013-9745-0

Kuzma J, Kokotovich A (2011) Renegotiating GM crop regulation. EMBO Rep 12(9):883-888

Lacey J, Lamont J (2013) Using social contract to inform social licence to operate: an application in the Australian coal seam gas industry. J Cleaner Prod (in press). doi: 10.1016/j. jclepro.2013.11.047

Ludlow KA (2004) Cultivating chaos: state responses to releases of genetically modified organisms. Deakin Law Rev 9(1):1-39

OECD (1986) Recombinant DNA safety considerations. OECD, Paris, France. http://dbtbiosafety.nic.in/guideline/OACD/ Recombinant_DNA_safety_considerations.pdf. Accessed 2 April 2014

OECD (1992) Safety considerations for biotechnology. OECD, Paris, France. http://dbtbiosafety.nic.in/guideline/OACD/ Safety_Considerations_for_Biotechnology_1992.pdf. Accessed 2 April 2014

OECD (1993) Safety considerations for biotechnology: Scale-up of Crop Plants. OECD, Paris, France. http://dbtbiosafety.nic. in/guideline/OACD/Scale_up_of_crop_plants.pdf. Accessed 2 April 2014

OGTR (2013a) Operations of the Gene Technology Regulator Annual report 2012-2013. www.ogtr.gov.au/internet/ogtr/ publishing.nsf/Content/reports-1. Accessed 2 April 2014

OGTR (2013b) Risk Analysis Framework (2013). http://www.ogtr. gov.au/internet/ogtr/publishing.nsf/Content/riskassessments1\#raf. Accessed 2 April 2014

Tasmanian Department of Primary Industries, Parks, Water and Environment (2013) Review of the moratorium on genetically modified organisms (GMOs) in Tasmania. Final Report. Australia. http://dpipwe.tas.gov.au/Pages/ document.aspx?path=/Documents/Final+Report_v.final_1612-13.pdf. Accessed 2 April 2014

The Allen Consulting Group (2011) Review of the Gene Technology Act 2000, undertaken for the Australian Department of Health and Ageing, Canberra, Australia. https://www.health.gov.au/internet/main/publishing.nsf/ Content/gene-techact-review. Accessed 2 April 2014

Whyte G (1989) Groupthink reconsidered. Acad Manag Rev 14(1):40-56. doi:10.2307/258190 